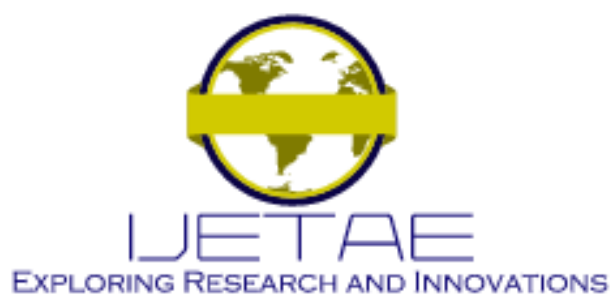

International Journal of Emerging Technology and Advanced Engineering

Website: www.ijetae.com (E-ISSN 2250-2459, Scopus Indexed, ISO 9001:2008 Certified Journal, Volume 11, Issue 06, June 2021)

Manuscript Received: 18 April 2021, Received in Revised form: 27 May 2021, Accepted: 05 June 2021 DOI: 10.46338/ijetae0621_01

\title{
Potable Water Order Forecasting System Using Data Mining Technique
}

\author{
Phatarapon Vorapracha \\ Division of Information Technology Management, Faculty of Industrial Technology, Phranakhon Rajabhat University, Bangkok, \\ 10220, Thailand.
}

\begin{abstract}
Potable water order forecasting system using data mining technique. It aims to analyze, design and develop potable water order forecasting system using data mining technique. There is a comparison data mining techniques were compared using the $\mathrm{C} 4.5$ algorithm and Bayesian classification algorithm. The researcher found that the $\mathrm{C4.5}$ algorithm is more suitable for drinking water ordering system. This web application system allows the system to predict each customer's drinking water orders. Subscription support ordering, drinking water and bank payment. In terms of user interaction and use the MySQL database program to organize the system database. The result of development potable water order forecasting system using data mining technique. Have tested data mining techniques were compared using the $\mathrm{C} 4.5$ algorithm and Bayesian classification algorithm. The researcher found that the $\mathrm{C} 4.5$ algorithm is more suitable for drinking water ordering system. From data research results using data in 9 months of training and 2 months of testing, it was found that the accuracy was $85.59 \%$. C4.5 algorithm and test the system from the evaluation of 2 administrators, 3 employees and 5 customers, total 10 people with average mean of 4.20 .
\end{abstract}

Keywords - Data mining, Drinking water

\section{INTRODUCTION}

Forecasting system for drinking water orders using datalike techniques. This is a solution to ordering drinking water. From the original problem, it was found that there were more customers. Causing ineffective customer care make some customers. Turned to consuming drinking water from other vendors causing the center to lose customers. From the above problems. The researcher then brings information technology. [1][2] To help solve problems in various areas that arise. The idea is to design and build information systems on web applications. By using data mining techniques to predict order to help minimize mistakes and increase sales in ordering of products. The system will notify customers of drinking water orders.
This work was developed to help customers in making decisions about purchasing drinking water by forecasting in this order. [3] Researchers have applied data mining techniques to assist in forecasting orders for customers.

\section{LITERATURE REVIEW}

The researchers conducted the following related research studies using the potable water order forecasting system using data mining technique.

A new web-based solution for modeling data mining processes. The conventional technologies and methods are not able to store and analyzed recent data that come from different sources: various devices, sensors, networks, transactional applications, the web, and social media. Due to a complexity of data, data mining methods should be implemented using the capabilities of the Cloud technologies. In this paper, a new web-based solution named DAMIS, inspired by the Cloud, is proposed and implemented. It allows making massive data mining simpler, effective, and easily understandable for data scientists and business intelligence professionals by constructing scientific work- flows for data mining using a drag and drop interface. The usage of scientific workflows allows composing convenient tools for modeling data mining processes and for simulation of real world time and resource-consuming data mining problems. The solution is useful to solve data classification, clustering, and dimensionality reduction problems. The DAMIS architecture is designed to ensure easy accessibility, usability, scalability, and portability of the solution. The proposed solution has a wide range of applications and allows to get deep insights into the data during the process of knowledge discovery. [4]

Non-Intrusive Load Monitoring (NILM) techniques have been leveraged by new instrument and machine learning algorithms to provide customers the breakdown of their energy usage. 


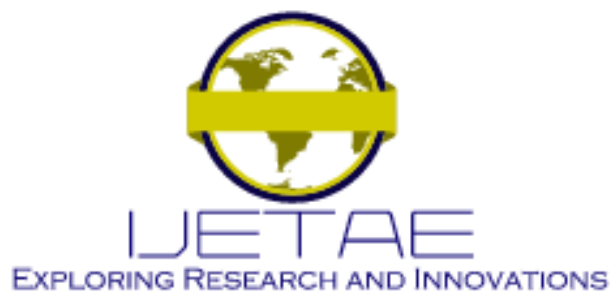

International Journal of Emerging Technology and Advanced Engineering

Website: www.ijetae.com (E-ISSN 2250-2459, Scopus Indexed, ISO 9001:2008 Certified Journal, Volume 11, Issue 06, June 2021)

The state-of-art indicates a large amount of highfrequency measurement $(>1 \mathrm{~Hz})$ can lead to accurate disaggregation. This paper, however, proposes a disaggregation algorithm relies on hourly smart meter readings, aiming to extend the application of the lowfrequency data that is accessible by both utilities and customers. The output of the disaggregation includes the breakdown of energy into load-category-based components that have different average power factors. The disaggregated data will support small-scale planning, e.g., in microgrid, by revealing the variance and patterns in different load categories. Our approach is built on a topdown structure that requires no prior knowledge or general models of individual loads. Using clustering and optimization techniques, we infer the load signatures of each category based on the active and reactive power from smart meters. The signatures are updated periodically using the most recent smart meter data. The results show that our disaggregation approach could be applied to random houses in different seasons and to single house and small neighborhood in both offline and quasi-real-time context.[5]

Data mining is an interdisciplinary field of computer science and is referred to extracting or mining knowledge from large amounts of data. Classification is one of the data mining techniques that maps the data into the predefined classes and groups. It is used to predict group membership for data instances. There are many areas that adapt Data mining techniques such as medical, marketing, telecommunications, and stock, health care and so on. The C4.5 can be referred as the statistic Classifier. This algorithm uses gain radio for feature selection and to construct the decision tree. It handles both continuous and discrete features. C4.5 algorithm is widely used because of its quick classification and high precision. This paper proposed a C4.5 classifier based on the various entropies (Shannon Entropy, Havrda and Charvt entropy, Quadratic entropy) instance of Shannon entropy for classification. Experiment results show that the various entropy based approach is effective in achieving a high classification rate.[6]

Naive Bayes is a classification algorithm which is based on Bayes theorem with strong and naïve independence assumptions. It simplifies learning by assuming that features are independent of given class. This paper surveys about naïve Bayes algorithm, which describes its concept, hidden naïve Bayes, text classification, traditional naïve Bayes and machine learning.
Also represents augmented naïve Bayes by examples. And at the end some applications of naïve Bayes and its advantages and disadvantages has discussed for a better understanding of the algorithm. [7]

\section{MATERIALS AND METHODS}

This paper is a data mining technique used in analysis. By comparing the two techniques as follows

\section{A. C4.5 Algorithm}

The C4.5 algorithm is used in greedy approach was applied to tree construction under the "top-down recursive divide-and-conquer" approach by considering the data set for learning training data, the set of records of the data. Each record consists of a set of attributes and attributes that describe the category of that record's data. By dividing information into smaller parts during the tree building process. [8]

Decision Tree Generation Algorithm It will need 3 inputs together, 1) $D$ means the data set to be considered. At the beginning of the run, the data set $D$ contains every record. 2) The list of attributes. Where which means The set of attributes used to characterize each record in the dataset, and 3) the method for selecting the attribute, which is the method for selecting the attribute. It is best to distinguish between the records in the dataset according to the category of the data. This attribute selection method uses attribute selection metrics such as information gain or gini index, etc. Attributes We may also need to consider the regulations and characteristics of the tree, for example the genie index is a measure that will work with binary trees. But as for the knowledge gain, it works with trees with multiple branches and allows multi-way split.[9]

Tree generation starts with only one node $N$, which represents all the data in the dataset.

In the event that every record in the $D$ dataset has the same category of data, node becomes a leaf node. And there will be $C$ categories attached steps (2) and (3). - Note step (4) and (5) is the termination condition. In step (6), the attribute selection method will be called to decide the criteria for dividing the data. The result is one of the best attributes that can separate records and categories from the dataset. Selecting an attribute can also tell which branches will grow from the $N$ node to divide the data into sections. If any part being divided contains all records with the same category as that segment, it is called a "pure partition".[10] 


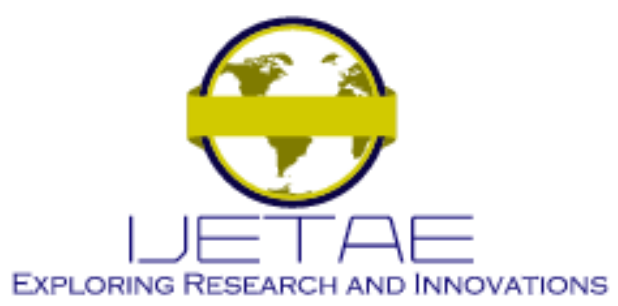

International Journal of Emerging Technology and Advanced Engineering

Website: www.ijetae.com (E-ISSN 2250-2459, Scopus Indexed, ISO 9001:2008 Certified Journal, Volume 11, Issue 06, June 2021)

Same is possible - by dividing the data, we must try to have the segmented portion contain as many records of the same category as possible.

The $N$ node is named with the attribute name obtained from step (6), and each branch growing from the $N$ node represents a possible growth in that attribute. The division of data and the addition of branches to the node $N$ in steps (10) and ((11 takes place under three conditions, with $A$ as an attribute. In other words, $A$ is a splitting attribute, where $A$ contains all possible values that occur in the dataset as $\{a 1, a 2, \ldots, a v\}$.

We have to start by calculating the value of Info $(D)$, also known as the entropy of $\mathrm{D}$, that is the mean of the amount of data required to identify a category of a record. In the data set it will depend on the ratio of the number of records corresponding to each category. Where can be calculated as follows

$$
\operatorname{Info}(D)=-\sum_{i=1}^{m} p_{i} \log _{2}\left(p_{i}\right)
$$

Where $p_{i}$ is the probability that a record has a category of data $c_{i}$, which can be calculated from $\frac{\left|c_{i, D}\right|}{|D|}$

Suppose we want to split the $D$ dataset into sub-datasets using attributes with different values occurring in the $v$ dataset. $(\{a 1, a 2, \ldots, a v\})$ if attribute $A$ has a discontinuous value. We will consider dividing the data set into $v$ subdatasets. Which can be divided into $(\{D 1, D 2, \ldots, D v\})$ where any $D j$ contains a set of records whose attribute $A$ has a value of $a j$, etc. Each subset corresponds to a subgrown that is extracted from the node. $N$ under consideration Therefore, in dividing a subset of data We must try to make each subset contain all of the same, categorized records.

We will need to calculate the value $\operatorname{Info}_{A}$ (D), which represents the amount of data expected to be used to divide the $D$ into sub-dataset. By considering the attributes that can be calculated as follows.

$$
\operatorname{Info}_{A}(D)=-\sum_{j=1}^{v} \frac{\left|D_{j}\right|}{D} \times \operatorname{Info}\left(D_{j}\right)
$$

$\frac{\left|D_{j}\right|}{D}$ Refers to the number of records in the data set $D$ whose value in attribute $A$ is $a_{j}$ divided by the total number of records in the data set $D$.
Calculate Info $(D)$ and $\operatorname{Info}_{A}(D)$ values. Knowledge gain for attribute determination $A$ can be calculated from the difference between the amount of data required to identify the category of data. For a record with the amount of data that is expected to be used for dividing the data set $D$ into sub-datasets. By considering the attributes that can be calculated as follows:

$$
\operatorname{Gain}(A)=\operatorname{Info}(D)-\operatorname{Info}_{A}(D)
$$

The value Gain $(A)$ indicates the amount of knowledge gain we will gain by considering the attribute $A$ and dividing the data set into subsets based on the attribute $A$ if the value Gain ( ) is the most valuable knowledge gain of all attributes. The attribute is the best attribute for classification. Divide data into sub-datasets . Because attribute $A$ requires the amount of data that. The least used for classification (minimal InfoA $(D)$ ).

\section{B. Bayesian Classification Algorithm}

1) The Issue of Classification most of us are already familiar with the concept of classification as we, more or less, use them every day. For example, when you see a stranger, your brain subconsciously determines that this person is either a man or a woman. [11] In fact, this is a sort of classification operation. From a mathematical standpoint, we can define classification problems as follows: Already Known Sets: $\{\mathrm{C}=\mathrm{y} 1, \mathrm{y} 2, \ldots, \mathrm{yn}\}$ and $\mathrm{I}=\{\mathrm{x} 1, \mathrm{x} 2, \ldots, \mathrm{xm}, \ldots\}$, determine the mapping rules $\mathrm{y}=\mathrm{f}(\mathrm{x}), 0$ is arbitrarily defined as any $x i \in I$, and only one item $y i \in C$ is $y i=f(x i)$ true. Where $C$ is called a collection of categories, each element is a category, and $\mathrm{I}$ is the name by which the item set is called with each element an item to be sorted, and $\mathrm{f}$ is called a classifier. The task of the classification algorithm is to construct the classifier f. [12] We will emphasize here that classification problems often use empirical methods to construct mapping rules. That is to say; general classification problems frequently lack enough information to construct a $100 \%$ correct mapping rule. However, through the experience of data learning, it is possible to achieve a certain probability of getting the correct classification. Therefore, the trained classifier does not necessarily need to accurately map each item to its classification. The quality of the classifier is related to the classification construction method, the characteristics of the classifiable data, and the number of samples provided. 


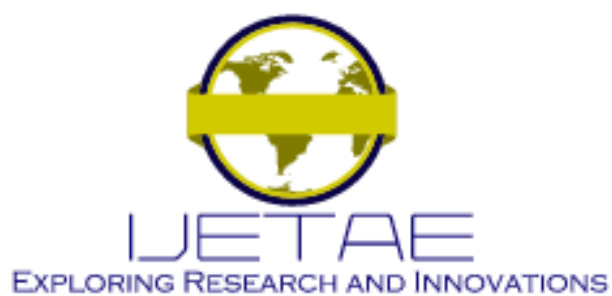

International Journal of Emerging Technology and Advanced Engineering

Website: www.ijetae.com (E-ISSN 2250-2459, Scopus Indexed, ISO 9001:2008 Certified Journal, Volume 11, Issue 06, June 2021)

2) Bayesian Classification Based on Bayes' the oremBayes' Theorem solves many problems that we often encounter in real life. [13] We can generalize most of these problems as follows: "Given that, an event has occurred (by assumption, presumption, assertion or evidence) what is the probability that a second event will occur?" We will express the already known condition as $\mathrm{P}(\mathrm{A} \mid \mathrm{B})$ and the event which is likely to potentially occur as $\mathrm{P}(\mathrm{B} \mid \mathrm{A})$. We will begin by explaining what conditional probability is: $\mathrm{P}(\mathrm{A} \mid \mathrm{B})$ indicates that event $\mathrm{B}$ has already occurred. The probability of event $A$ is called the conditional probability of event $\mathrm{A}$ in event $\mathrm{B}$. The basic solution formula is:

$$
P(A \mid B)=\frac{P(A B)}{P(B)}
$$

Bayes' Theorem is useful because we often encounter this sort of thing in our daily lives: we can easily draw a direct conclusion $\mathrm{P}(\mathrm{A} \mid \mathrm{B})$, but $\mathrm{P}(\mathrm{B} \mid \mathrm{A})$ is harder to infer directly. However, we're more concerned about $\mathrm{P}(\mathrm{B} \mid \mathrm{A})$. Bayes Theorem is the path that lets us travel from $\mathrm{P}(\mathrm{A} \mid \mathrm{B})$ to $\mathrm{P}(\mathrm{B} \mid \mathrm{A})$. The below is Bayes' Theorem without proofs:

$$
P(B \mid A)=\frac{P(A \mid B) P(B)}{P(A)}
$$

\section{3) Three Stages of the Naive Bayesian Classification}

Stage 1: Preparatory. Work Stage In this stage, we do the necessary preparation for Naive Bayesian classification. [14] The main task is to determine the characteristics of the attributes according to the attributes' specific conditions and to perform the appropriate division of each feature attribute. Then, we select a portion of the classification for sampling and use it to form the training sample set. The input for this stage is all the classifiable data, and the output is the characteristic attributes and training samples. This stage is the only stage in the whole of naive Bayesian classification where the quality of the work performed will have a heavy influence on the whole process. The characteristics of the attributes, classification of the characteristic attributes, and the quality of the training samples decide the quality of the classifiers.

Stage 2: Classifier Training Stage. In this stage, we generate a classifier. [15] The main task is to calculate the frequency of appearance of each category in the training samples and the conditional probability estimation of each category for each feature attribute and to record the results.
The inputs are feature attributes and the training sample; the outputs are classifiers. This stage is a mechanical one; it is based on the formula discussed above, and we can automatically calculate it completely by a program.

Stage 3: Application Stage. [16] The task in this stage is to classify the classification items using the classifier. The inputs are the classifier and the classifiable items, and the output is the mapping between the classifiable items and the categories. This stage is also a mechanical and we can complete it through the program.

4) Semi-naive Bayesian Classification in Naive Bayesian Classification, we assumed the independence of the various attributes. We did this for convenience in computation and to prevent an excessively large number of computations caused by the dependence of excessive attributes. Therefore, we call it "naïve." Although the overall effect achieved by native Bayesian classification is not bad, this is possible because the attributes are related to each other. [17] The properties of one attribute depend on the properties of another. Therefore, these are semi-naive Bayesian classifiers. To limit the size of calculations, we must assume that each attribute relies only on one other attribute. In this way, a more accurate description of the real situation is possible.

$$
P(c \mid x) \propto P(c) \prod_{i=1}^{d} P\left(x_{i} \mid c, p a_{i}\right)
$$

The formula becomes pai Attributes for xi the dependent attribute become the xi parent attribute.

\section{Study area and Data}

The study area of this research used drinking water transportation information from the drinking water transportation company from January to November 2020, a total of 300 people were obtained by the researcher from the data form used for the training from January to September 2020 and the data used for testing from October to November 2020.

\section{REsUlts AND DisCUSSION}

The results of potable water order forecasting system using data mining technique. The period of time used for data use is defined as shown in Table 1. 


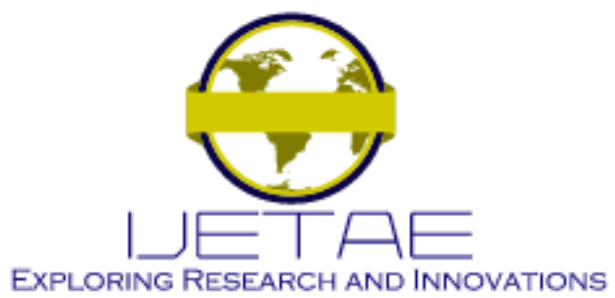

International Journal of Emerging Technology and Advanced Engineering

Website: www.ijetae.com (E-ISSN 2250-2459, Scopus Indexed, ISO 9001:2008 Certified Journal, Volume 11, Issue 06, June 2021)

TABLE 1

Period of use of information

\begin{tabular}{|c|c|c|}
\hline Data-Time & Training & Testing \\
\hline \multirow{2}{*}{ Month } & January to & October to November \\
& September 2020 & 2020 \\
\hline
\end{tabular}

Table 1, the period is classified using the Training data of january to september 2020 and the testing data of october to november 2020 . The number of 300 record. The forecast uses two methods to compare forecasting, C4.5 algorithm and the Bayesian classification algorithm, using the factor in Table 2.

TABLE 2

Factor potable water order forecasting

\begin{tabular}{|c|l|l|}
\hline No. & \multicolumn{1}{|c|}{ Category } & \multicolumn{1}{c|}{ Tpye } \\
\hline $\mathbf{1}$ & Drinking water order type & Bottle, Bucket \\
\hline $\mathbf{2}$ & $\begin{array}{l}\text { Distance, date of ordering } \\
\text { drinking water }\end{array}$ & 7 days / week \\
\hline $\mathbf{3}$ & Gender & Male, Female \\
\hline $\mathbf{4}$ & Customer & $\begin{array}{l}\text { General customers, } \\
\text { Company }\end{array}$ \\
\hline
\end{tabular}

Table 2, it is the determination of the factors used in forecasting the purchase of drinking water.

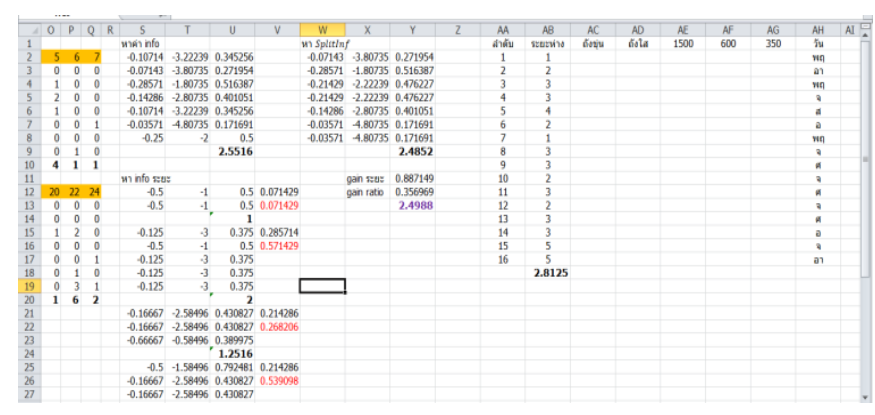

Fig. 1 Classification of data using the $\mathrm{C} 4.5$ algorithm

Figure 1 shows the usage classification of data using the C4.5 algorithm. Researcher can know the term info, gain distance, splitinf, gainrati and the accuracy value.

The researcher conducted tests from people who ordered drinking water products and make a forecast with Testing data, it was found to be correct as in Figure 2.

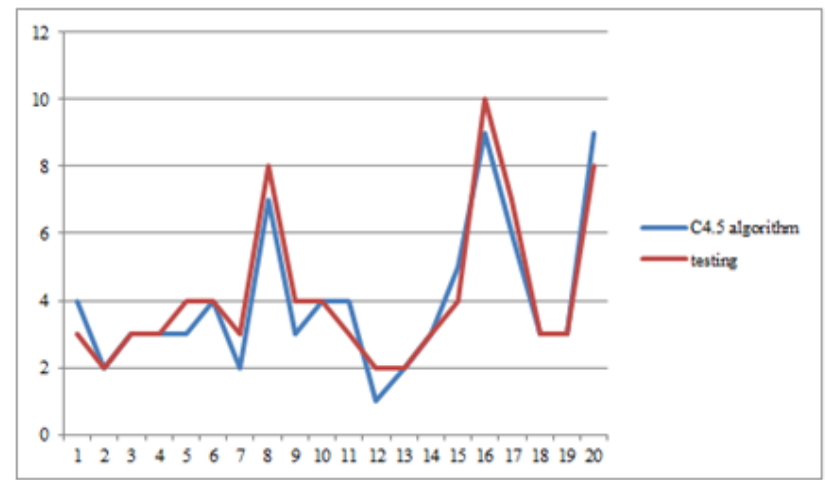

Fig. 2 The graph shows a forecast by the $\mathbf{C} 4.5$ algorithm and the testing data.

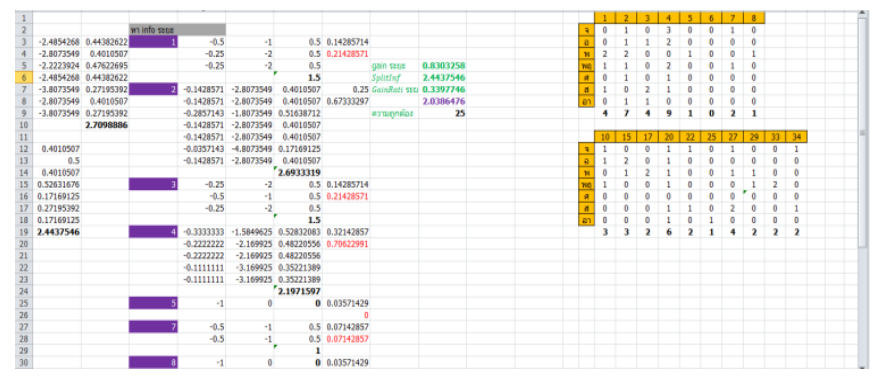

Fig. 3 Classification of data by Bayesian classification algorithm

Figure 3 shows the usage classification of data using the Bayesian classification algorithm. Researchers can know the term info, $\mathrm{P}(\mathrm{A} \mid \mathrm{B}), \mathrm{P}(\mathrm{B} \mid \mathrm{A})$ and the accuracy value.

The researcher conducted tests from people who ordered drinking water products and make a forecast with Testing data, it was found to be correct as in Figure 4.

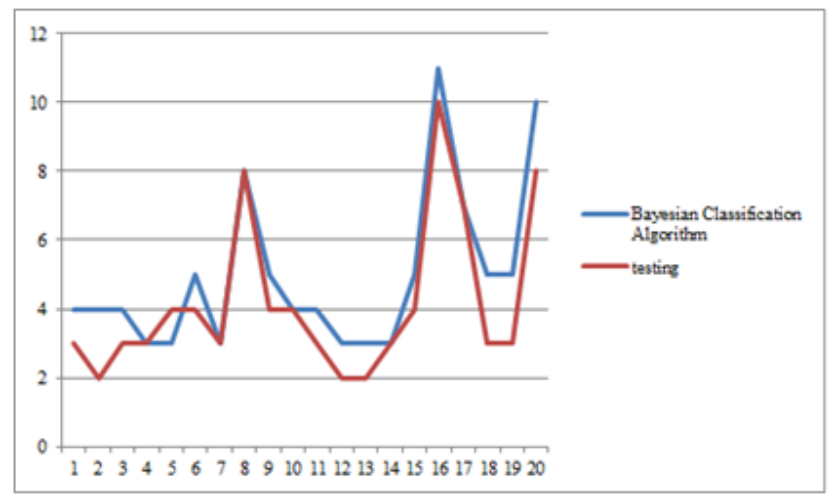

Fig. 4 The graph shows a forecast by the Bayesian classification algorithm and the testing data. 


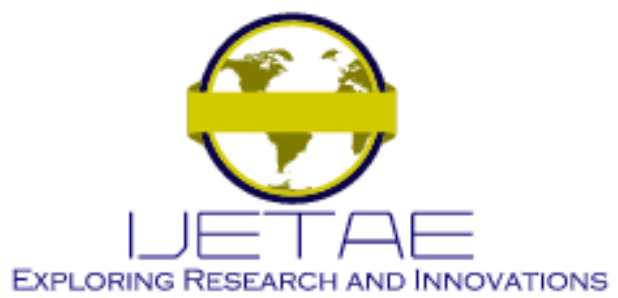

International Journal of Emerging Technology and Advanced Engineering

Website: www.ijetae.com (E-ISSN 2250-2459, Scopus Indexed, ISO 9001:2008 Certified Journal, Volume 11, Issue 06, June 2021)

The researcher compared the drinking water consumption forecast by comparing $\mathrm{C} 4.5$ algorithm, Bayesian classification algorithm and data testing as shown in Figure 5. It was found that the C4.5 algorithm forecast method was more accurate than the Bayesian classification algorithm. The researcher therefore selected the forecast method to be applied to the drinking water purchase forecasting system.

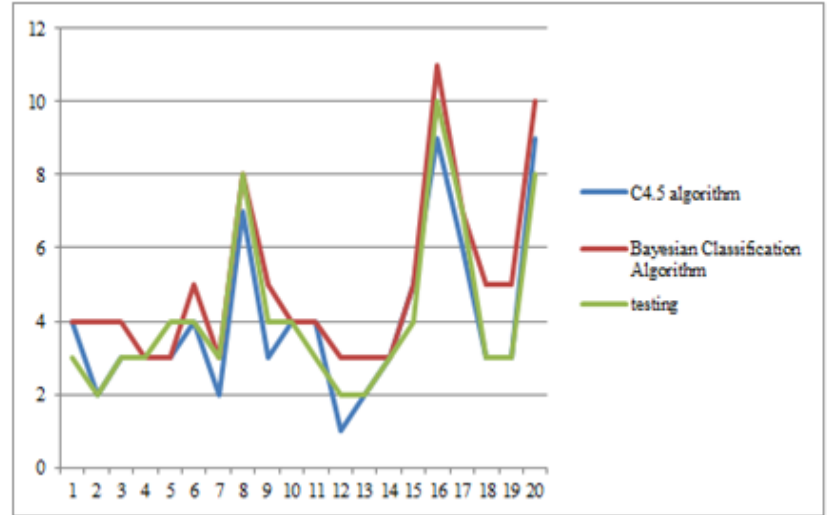

Fig. 5 The graph shows a forecast by the $\mathrm{C} 4.5$ algorithm, Bayesian classification algorithm and the testing data.

The C4.5 algorithm is used in the drinking water purchase forecasting system. The researcher designed the following sections: Administrators can login, employee list information, list customers, list of drinking water, list all orders, deal with product information, and drinking water order information can be added/ deleted/ edited. Employees can login, employee list information, customer list and manage drinking water order information can be added/ deleted/ edited. Customers can login, price products list, able to place orders for drinking water at the system to make order forecast by allowing customers to make forecasting decisions using techniques like information from shopping cart pages. Purchase history of drinking water can set up a user account and contact us page. Potable water order forecasting system using data mining technique the use case diagram design data is shown in Figure 6.

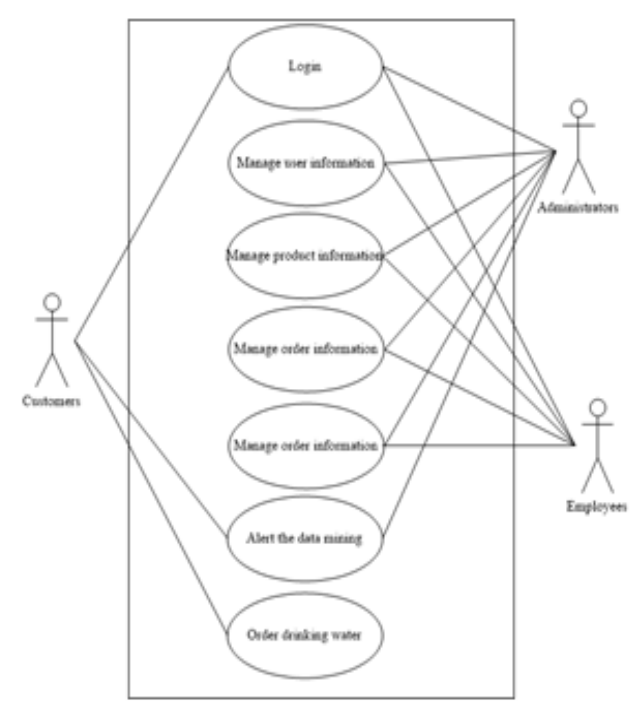

Fig. 6 Use case diagram

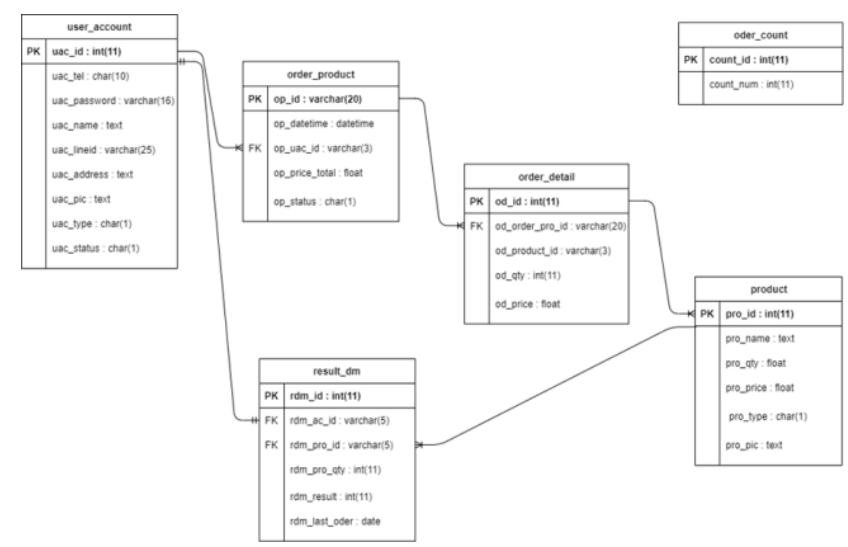

Fig. 7 ER model web application potable water order forecasting

Figure 7 shows the E-R model to store drinking water purchase data in the database. By collecting customer drinking water order data With the said information can be used in forecasting. 


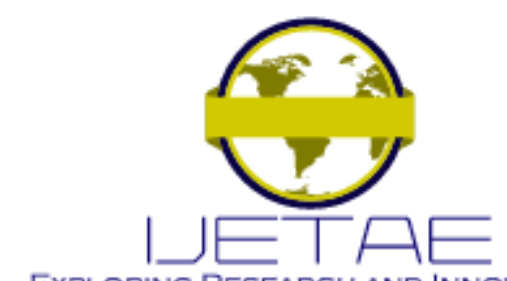

EXPLORING RESEARCH AND INNOVATIONS

International Journal of Emerging Technology and Advanced Engineering

Website: www.ijetae.com (E-ISSN 2250-2459, Scopus Indexed, ISO 9001:2008 Certified Journal, Volume 11, Issue 06, June 2021)

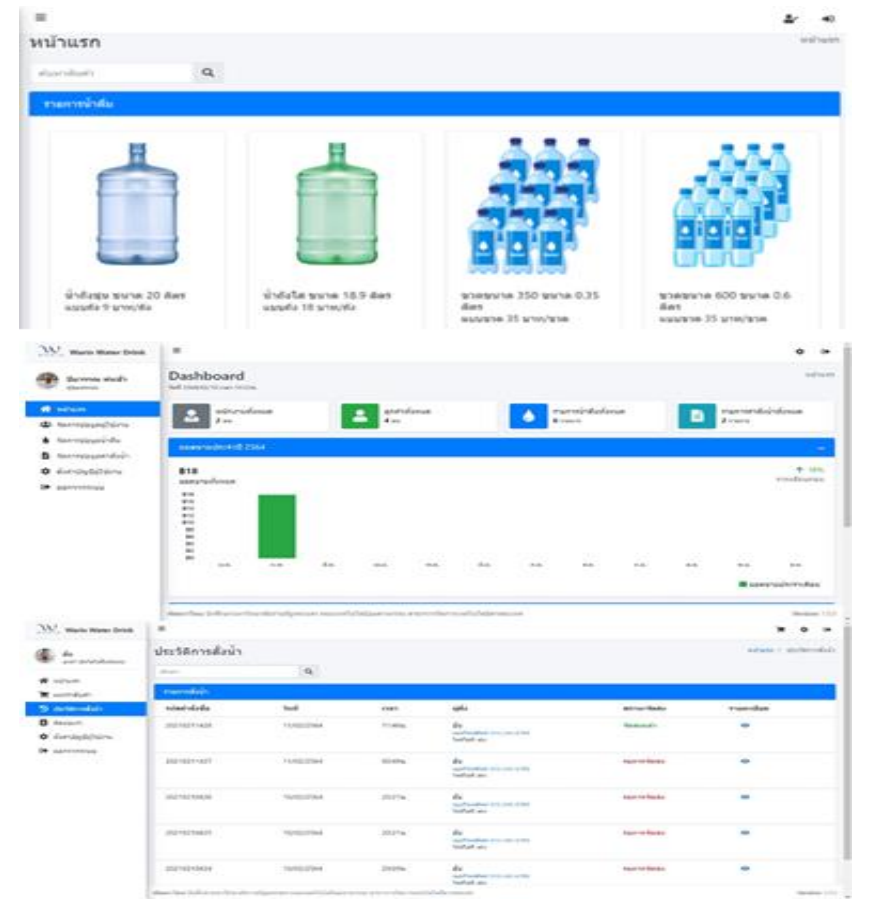

Fig. 8 Example web application potable water order forecasting system using data mining technique

Figure 8 shows web application to order products for customers a preview of the orders obtained from the forecast. Using data as an example to support decisionmaking for customers.

Potable water order forecasting system using data mining technique to be used by system administrators, employees and customers. Satisfaction of the system can be assessed as shown in Table 3.

TABLE 3

Assess the satisfaction of the system

\begin{tabular}{|l|c|}
\hline \multicolumn{1}{|c|}{ Satisfaction measurement issues } & Average \\
\hline 1. The system is easy to use, not complicated. & 4.15 \\
\hline 2. The system is very fast to process. & 4.22 \\
\hline $\begin{array}{l}\text { 3. The system helps customers decide when } \\
\text { buying drinking water. }\end{array}$ & 4.23 \\
\hline 4. There is the security of the system. & 4.20 \\
\hline $\begin{array}{l}\text { 5. The system helps provide accurate order } \\
\text { notification. }\end{array}$ & 4.20 \\
\hline 6. Overall satisfaction of the system & 4.22 \\
\hline \multicolumn{1}{|c|}{ Summation } & $\mathbf{4 . 2 0}$ \\
\hline
\end{tabular}

\section{CONCLUSIONS}

Potable water order forecasting system using data mining technique. Data mining techniques were compared using the $\mathrm{C} 4.5$ algorithm and Bayesian classification algorithm. The researcher found that the $\mathrm{C} 4.5$ algorithm is more suitable for drinking water ordering system. Using 9 months of training data and 2 months of testing data, it was found to be $85.59 \%$ accurate. The above information is used for web application ordering drinking water. Found that the customer was notified and help in deciding the number of orders for customers to meet the needs of customers.

\section{Acknowledgment}

This study was supported by Division of Information Technology Management, Faculty of Industrial Technology, Phranakhon Rajabhat University, Thailand.

\section{REFERENCES}

[1] H.-G. Acosta-Mesa , N. Cruz-Ramírez , R. Hernández-Jiménez , Aceto-white tem- poral pattern classification using k-nn to identify precancerous cervical lesion in colposcopic images, Comput. Biol. Med. 39 (9) (2009) 778-784 .

[2] K.A. Albashiri , F. Coenen , Agent-enriched data mining using an extendable framework, in: Agents and Data Mining Interaction, Springer (2009) 53-68 .

[3] W.-T. Lo , Y.-S. Chang , R.-K. Sheu , C.-C. Chiu , S.-M. Yuan , Cudt: a cuda based decision tree algorithm, Sci. World J. 2014 (2014) 12.

[4] Viktor Medvedev, Olga Kurasova, Jolita Bernatavi, Povilas Treigys , Virginijus Marcinkevi cius, Gintautas Dzemydaa. A new webbased solution for modelling data mining processes. Simulation Modelling Practice and Theory 76 (2017) 34-46.

[5] Guanchen Zhanga, G. Gary Wanga, Hassan Farhangi, Ali Palizban. Data mining of smart meters for load category based disaggregation of residential power consumption. Sustainable Energy, Grids and Networks 10 (2017) 92-103.

[6] Seema Sharma, Jitendra Agrawal, Sanjeev Sharma. Classification Through Machine Learning Technique: C4.5 Algorithm based on Various Entropies. International Journal of Computer Applications 82(16)(2013) 20-27.

[7] Pouria Kaviani, Sunita Dhotre. Short Survey on Naive Bayes Algorithm. International Journal of Advance Engineering and Research Development 4 (11)(2017) 607-611.

[8] H.-L. Nguyen , Y.-K. Woon , W.-K. Ng , A survey on data stream clustering and classification, Knowl. Inf. Syst. (2014) 1-35.

[9] T. Sharp , Implementing decision trees and forests on a gpu, in: Computer Vi- sion-ECCV 2008, Springer (2008) 595-608.

[10] X.-Y. Wang, X.-J. Zhang, H.-Y. Yang, J. Bu , A pixel-based color image segmenta- tion using support vector machine and fuzzy cmeans, Neural Netw. 33 (2012) 148-159 . 


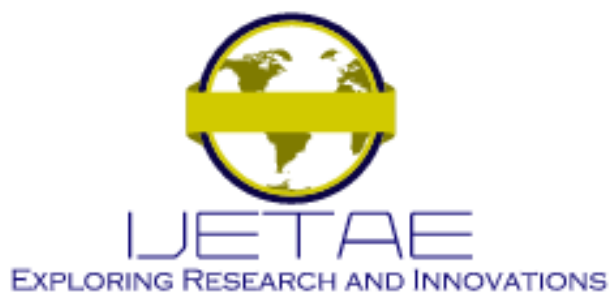

International Journal of Emerging Technology and Advanced Engineering Website: www.ijetae.com (E-ISSN 2250-2459, Scopus Indexed, ISO 9001:2008 Certified Journal, Volume 11, Issue 06, June 2021)

[11] J. Xu , L. Yao , L. Li , Y. Chen , Sampling based multi-agent joint learning for as- sociation rule mining, in: Proceedings of the 2014 International Conference on Autonomous Agents and Multi-Agent Systems, International Foundation for Autonomous Agents and Multiagent Systems (2014) 1469-1470

[12] C. Moemeng, V. Gorodetsky, Z. Zuo, Y. Yang, C. Zhang, Agentbased distributed data mining: a survey, in: Data Mining and MultiAgent Integration, Springer (2009) 47-58 .

[13] N. Zhong , Y. Matsui , T. Okuno , C. Liu , Framework of a multiagent kdd sys- tem, in: Intelligent Data Engineering and Automated Learning - IDEAL 2002, Springer (2002) 337-346.
[14] I. Yoo, P. Alafaireet, M. Marinov, K. Pena-Hernandez, R. Gopidi, J.F. Chang,L. Hua, Data mining in healthcare and biomedicine: a survey of the literature, J.Med. Syst. 36 (4) (2012) 2431-2448.

[15] Jackson, J. Data mining: a conceptual overview. Communications of the Association for Information Systems 8 (1): 19.m (2002).

[16] Ngai, E.W.T., Hu, Y., Wong, Y.H., Chen, Y., Sun, X. The application of data mining techniques in financial fraud detection: a classification framework and an academic review of literature. Decis. Support. Syst. 50 (3) (2011) 559-569.

[17] Beynon, M.J., Peel, M.J., Tang, Y.C. The application of fuzzy decision tree analysis in an exposition of the antecedents of audit fees. Omega 32 (3) (2004) 231-244. 